\title{
A mídia regional e representação social da violência: o caso dos refugiados venezuelanos no norte do Brasil
}

\author{
Marco Paulo Andradel \\ Sheila Maria Doula²
}

\section{Resumo}

Nos últimos anos as migrações internacionais têm alcançado grande espaço nos debates políticos e nos meios de comunicação. No âmbito das migrações, os refugiados configuram-se como um grupo em particular. Eles, muitas vezes, são representados como invasores e alvos de violência física e simbólica. A mídia tem o poder de produzir narrativas e acontecimentos, sendo capaz de influenciar, criar ou ressignificar essas representações. Frente a esse contexto, pretende-se com este artigo investigar como a mídia televisiva tem representado as violências vivenciadas pelos refugiados venezuelanos no norte do Brasil. Foi analisado um total de 129 reportagens televisionadas pelo Bom Dia Amazônia, Jornal de Roraima e Jornal do Amazonas. Em um primeiro momento os títulos foram analisados através do Iramuteq, separando as reportagens em categorias. Posteriormente, as reportagens foram transcritas e analisadas por meio da análise de conteúdo. Os resultados apontam uma ambiguidade discursiva entre a crise humanitária e a xenofobia.

Palavras-chave: Imigração. Telejornal. Vulnerabilidade. Crise humanitária.

\section{Regional media and social representation of violence: the case of Venezuelan refugees in north of Brazil}

1 Doutorando do programa de Pós-Graduação em Extensão Rural, da Universidade Federal de Viçosa (UFV). Bolsista do CAPES, membro do Observatório da Juventude Rural (UFV) e do grupo de pesquisa Meios (UFV).

2 D. Sc. em Antropologia Social pela Universidade de São Paulo (USP). Professora do Departamento de Economia Rural da Universidade Federal de Viçosa (UFV); orientadora do Programa de Pós-Graduação em Extensão Rural da mesma instituição. Bolsista de Produtividade CNPQ; coordenadora do Observatório da Juventude Rural (UFV) e do projeto de pesquisa Mobilidade socioespacial e trajetórias migratórias entre as gerações de famílias rurais (FAPEMIG). 


\section{Abstract}

In recent years, the international migrations have gained a great deal of attention in political debates and in the media. In the migration context, refugees are considered a particular group. They are often shown as invaders and targets of physical and symbolic violence. The media has the power of producing narratives and events, what makes it be able to influence, create or give a new meaning to these representations. Faced to this context, the aim of this study to investigate how the television media has represented the violence experienced by Venezuelan refugees in north of Brazil. For this, 129 articles, published by Bom dia Amazônia, Jornal de Roraima and Jornal do Amazonas, were analyzed. At first, the titles were analyzed using the Iramuteq software, separating articles into categories. Subsequently, the reports were transcribed and analyzed by content analysis. The results indicate a discursive ambiguity between the humanitarian crisis and the xenophobia.

Keywords: Immigration. Television news. Vulnerability. Humanitarian crisis.

\section{Introdução}

Nos últimos anos o Brasil tem se configurado como destino de imigrantes de diversas nacionalidades, especificamente a partir do ano de 2008, em decorrência da crise econômica mundial e do fortalecimento econômico do país naquele período (COGO, 2015, 2016). Segundo os dados da Relação Anual de Informações Sociais, o número de imigrantes no mercado de trabalho formal aumentou 131\% entre 2010 a 2015 e apesar deste crescimento, verifica-se que os imigrantes correspondem a menos de $0,5 \%$ dos trabalhadores do país (BRASIL, 2017), destacando-se que os trabalhos informais realizados por imigrantes ilegais não se encontram contabilizados. Uma estimativa do governo brasileiro aponta que em 2014 havia aproximadamente um milhão de imigrantes ilegais residindo apenas no estado de São Paulo.

No âmbito das migrações, os refugiados configuram-se como um grupo particular. A maior visibilidade dos refugiados está relacionada a catástrofes ambientais e à ocorrência de guerras civis em dimensões geopolíticas (OLIVEIRA, 2006). Neste sentido, os indivíduos, famílias ou grupos são forçados a se deslocarem para outros países em função de conflitos étnicos, religiosos, regimes autoritários e a violação dos direitos humanos; esses sujeitos veem-se coagidos a fugir de seu país tendo como princípio a proteção de suas vidas (MOREIRA, 2010).

Os dados do Alto Comissariado das Nações Unidas para os Refugiados - ACNUR - apontam que até o primeiro semestre de 2016, 3,2 milhões de pessoas abandonaram 
suas residências e encontravam-se refugiadas em decorrência de conflitos e (ou) perseguições (ACNUR, 2016).

Atualmente o Brasil reconhece um total de 10.145 refugiados de 82 nacionalidades residentes no país (CONARE, 2018). As informações do CONARE mostram que em 2016 houve uma redução de $64 \%$ dos pedidos de refúgio em relação ao ano de 2015 , e isso se explica devido à diminuição de pedidos de cidadãos haitianos. Já em 2017 verifica-se um aumento de $228 \%$ nos pedidos de refúgio, totalizando 33.866 solicitações. Estes mesmos dados mostram um aumento expressivo dos pedidos de refugiados venezuelanos, com 17.865 solicitações em 2017. O crescimento exponencial desses refugiados em terras brasileiras é um dos resultados da instabilidade política, econômica e social que assola a Venezuela.

A escolha do Brasil como um país de acolhimento pode ser justificada por três motivos. O primeiro deles diz respeito à proximidade entre as fronteiras. Rodrigues (2006) argumenta que a fiscalização só é realizada

[...] em momentos específicos e esporádicos de alguma campanha contra o contrabando de combustível ou contra o tráfico de mulheres. Dessa forma, a facilidade de acesso via terrestre e a pouca fiscalização favorecem o fluxo de migrantes ilegais que cruzam a fronteira tanto para se estabelecerem em Boa Vista e Pacaraima, como em Santa Elena e outras cidades vizinhas na Venezuela (RODRIGUES, 2006, p. 201).

O segundo consiste no fato de o Brasil ter sido pioneiro na América Latina a sancionar uma lei (Lei Federal no. 9.474/9733) específica para os refugiados (AYDOS et al, 2008). Já o terceiro motivo está ligado ao fato de que os refugiados acolhidos no Brasil recebem o apoio de organizações governamentais e não governamentais com assistência médica, moradia, alimentação, proteção jurídica e mediações/serviços que tentam promover sua integração local (UNHCR, 2002).

A integração local dos refugiados é um processo desafiador e complexo, uma vez que envolve não apenas fatores de cunho jurídico e governamental, mas também aspectos socioculturais (CRISP, 2004). A presença de elementos culturais similares entre o local de origem e o de destino poderia por vezes ser facilitador do processo de integração local (CRISP, 2004). Contudo, os estrangeiros geralmente são vistos como indesejados, invasores que não compartilham dos mesmos códigos socioculturais

${ }^{3}$ Define quem pode ser considerado refugiado, suas obrigações, direitos e deveres em território nacional. 
(SAYAD, 1988) e, como "outsiders", passam a lidar com a indiferença e a violência, como a exploração, a discriminação e o preconceito dos "estabelecidos" (ELIAS, SCOTSON, 2000).

A violência surge em um contexto social de interação entre as identidades e diferentes percepções de mundo. Essas identidades são dependentes das representações sociais, construídas cultural e socialmente e circulam por várias formas e veículos de comunicação. A televisão, como um dos veículos midiáticos de maior expressão no Brasil, torna-se um dos principais difusores e influenciadores das representações.

Sabe-se que cada grupo social elabora seu próprio sistema de representações a partir de condutas, práticas e ações e que estas representações funcionam como referências que dão suporte para compreender a vida social. Entende-se então a chegada de refugiados venezuelanos ao Brasil, "assim como outras ocorrências a ela relacionadas, como acontecimentos, que interpelam e agenciam diferentes atores, instituições e discursos em torno de questões coletivas que essa imigração suscita" (COGO, 2016). Seguindo este argumento, o objetivo deste artigo é analisar como a mídia televisiva, ao participar das interações sociais e propiciar circulação das representações, constrói para seu público o "acontecimento" das migrações e as violências vividas pelos refugiados venezuelanos. Toma-se como corpus para análise os programas de TV Bom dia Amazônia, Jornal do Amazonas e Jornal de Roraima, jornais vinculados a Rede Globo e filiais.

\section{Teoria das Representações Sociais}

Revisitando a teoria das representações coletivas de Durkheim, Moscovici formula a teoria de representações sociais. As representações sociais são elaboradas no meio social, e tem como finalidade tornar o estranho em familiar através da transformação de imagens e ideias pré-estabelecidas, além de mediar as relações entre os sujeitos (JODELET, 2001; SÊGA, 2000; MOSCOVICI, 2010). Por surgirem no meio social, as representações constroem uma realidade compartilhada, criando uma conexão entre o imaginário e o mundo material (JODELET, 2001; SÊGA, 2000).

O imaginário, como expressão do pensamento, se manifesta por meio de discursos e imagens que atribuem sentido à realidade (PESAVENTO, 1998), e é a partir da construção do imaginário e no convívio social que as representações se difundem. 
Logo, as representações não são autoexplicativas, uma vez que a sua manifestação está condicionada às vivências de quem the atribui significado. Por consequência, as representações só serão compreendidas e codificadas pelos sujeitos que compreendem os símbolos e o contexto de onde elas emergem.

Pode-se dizer que nas relações entre os indivíduos, as representações norteiam os comportamentos e as comunicações sociais, intervindo, também, em processos de transmissão de conhecimento e na constante construção das identidades (JODELET, 2001). Enfatiza-se a importância da comunicação e das mídias, uma vez que as mesmas permitem a (re)criação das representações que serão compartilhadas pelos grupos e que /serão mantidas, ou não, em função do seu "grau de aceitação, socialização e capacidade mobilizadora" (PESAVENTO, 1998, p. 55).

As representações orientam as condutas que são próprias de cada sociedade. Assim, a teoria das representações sociais nos convida a entender os contextos onde as representações são criadas. Suas contribuições para este trabalho centram-se na possibilidade de discutir a representação sobre os refugiados venezuelanos disseminada pela mídia brasileira, entendendo-a como criadora e difusora de imagens e discursos que podem influenciar e (re)significar as representações sociais sobre as migrações.

\section{A mídia e as Representações Sociais}

Repertórios de ideias, imagens e valores sociais que figuram no imaginário podem ser entendidos como respostas aos estímulos propiciados pelo ambiente sociocultural e pelas transformações de ordem econômica, histórica ou tecnológica que configuram novas realidades (MOSCOVICI, 2010).

No mundo contemporâneo, a globalização e o desenvolvimento das tecnologias de informação e comunicação tornaram capaz a transmissão de notícias em tempo real em grande escala geográfica. As mensagens circulam livremente e as narrativas midiáticas aumentam sua capacidade de influenciar opiniões e comportamentos, assim como de sancionar ou reorientar conteúdos simbólicos.

Os telejornais diariamente veiculam informações por meio de imagens e sons, e têm a capacidade de instigar opiniões populares sobre os acontecimentos cotidianos ou extraordinários. São um território simbólico e assumem um papel fundamental na veiculação de ideias no imaginário popular (DARDE, LEME, 2016). Assim, os textos das 
[...] reportagens, as fotografias que ilustram as legendas das fotos e a própria estrutura das reportagens veiculadas pela imprensa, ao mesmo tempo em que contribuem para a formação ou transformação da visão de mundo do público, refletem os interesses e anseios de determinados grupos sociais [...] (BUENO, 2002, p. 101).

Entende-se, então, que a vinda dos refugiados como "acontecimento", bem como midiatização dessas migrações, viabilizam e produzem histórias, uma representação "imagética contemporânea da mobilidade humana, evocando essa imigração associada especialmente a risco, ameaça, descontrole, chegada massiva, invasão" (COGO, 2017, p.12).

A mídia, para além de veicular informações, produz representações. Na medida em que o incomum gera audiência, os cotidianos não são interessantes para os telejornais. Assim, as reportagens tendem a se concentrar em aspectos excêntricos do cotidiano, como violência, marginalização, entre outros (COGO, 2006; 2012; CHAMPAGNE, 2003). Cabe evidenciar que as populações marginalizadas, como no caso dos refugiados, tornam-se "notáveis" e singulares quando retratadas pela mídia (CHAMPAGNE, 2003).

\section{Procedimentos metodológicos}

Trata-se de uma pesquisa documental e de caráter exploratório. Esse tipo de pesquisa envolve a análise de materiais escritos (cartas, jornais, etc.) e materiais não escritos (vídeos, fotografias, programas de TV, etc.) (LAKATOS, MARCONI, 2001). Esse estudo orienta-se, ainda, por uma perspectiva qualitativa, na qual o pesquisador é parte integrante do processo de conhecimento, interpretando os fenômenos e buscando o significado das ações sociais (LAKATOS, MARCONI, 2001; COGO, 2012).

O campo empírico se constitui no ambiente virtual, no site globo.com, vinculado à Rede Globo de Televisão. A TV Globo foi inaugurada 1965 e foi o embrião do que viria a ser Rede Globo de Televisão, uma das maiores redes de televisão comercial do mundo e a maior do Brasil. São ao todo 123 filiais ou emissões próprias vinculadas ao Grupo Globo, além da Globo Internacional e dos canais pagos e serviços por assinatura, tendo um alcance de 98,56\% do território brasileiro (GLOBO, 2013).

O material analisado se constitui no corpus de reportagens apresentadas em três telejornais regionais vinculados à Rede Globo: Bom dia Amazônia, Jornal de Roraima e Jornal do Amazonas. A escolha pelos referidos telejornais se deu pela grande audiência e 
por serem formatos midiáticos que transmitem diariamente notícias das cidades nas quais se verifica a chegada dos refugiados venezuelanos.

A amostra relativa aos jornais Bom dia Amazônia, Jornal de Roraima e Jornal do Amazonas apresentou um total de 273 reportagens televisionadas no intervalo de fevereiro de 2017 a dezembro de 2018. Janeiro de 2017 não se encontra no corpus amostral por não estarem disponíveis no site dos telejornais as reportagens veiculadas durante esse mês. De posse das reportagens, o material foi decupado (transformado em texto) e analisado.

Inicialmente analisou-se os títulos das reportagens utilizando o software Interface de $R$ pour analyses Multidimensionnelles de Textes et de Questionnaires (Iramuteq), 0.7 Alpha2. O software permite realizar uma análise lexical quantitativa considerando a palavra como uma unidade de texto e sua contextualização dentro do corpus textual. Posteriormente, foram analisados os conteúdos das reportagens, considerando as falas dos repórteres, dos entrevistados e as imagens transmitidas (LAKATOS, MARCONI, 2001).

\section{Resultados e discussão}

Desde o final do ano de 2016, a chegada de venezuelanos à Região Norte do Brasil, mais especificamente nas cidades de Boa Vista - RR e Manaus - AM, tem sido amplamente visibilizada pela mídia brasileira. A televisão, como veículo midiático de maior expressão no Brasil, vem sendo um dos principais difusores de informação sobre este evento (COGO, 2016).

Analisando os títulos das reportagens com o auxílio do software Iramuteq 0.7 Alpha2 tem-se um corpus constituído por 129 segmentos de texto (ST), com aproveitamento de 110 STs (85,27\%). Emergiram 1.402 ocorrências (palavras, formas ou vocábulos), sendo 384 palavras distintas e 234 palavras ocorrendo uma única vez, possuindo uma frequência de ocorrência média por palavra de 17,05\% e 62,24\% por ST. Por meio da Classificação Hierárquica Descendente ( $C H D)$ foram geradas três classes de segmentos de texto distintas (Figura 1.): Classe 1, com 42 ST (38,18\%); Classe 2, com 28 ST (25,45\%); e Classe 3, com 40 ST (36,36\%). Estas foram categorizadas respectivamente como: Refugiados em Boa Vista, Refugiados em Manaus e Instituições governamentais. Tal categorização se deu em função da distribuição de palavras entre as classes e os respectivos segmentos de texto nos quais se encontram. O critério utilizado 
para permanência das palavras nas respectivas classes foi a adoção do valor de quiquadrado $\left(X^{2}\right)$ igual ou superior a 3.84, proporcionando um grau de liberdade igual a $1 \mathrm{em}$ uma margem de erro < 0,5 (CAMARGO, JUSTO, 2013).

Figura - 1: Dendograma da classificação hierárquica descendente dos títulos das reportagens.

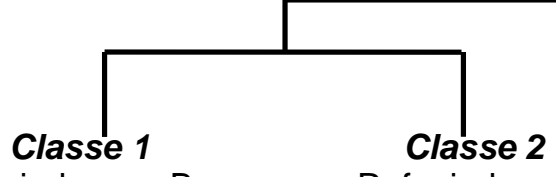

Refugiados em Boa Vista

\begin{tabular}{ll}
\hline & $\boldsymbol{X}^{2}$ \\
\hline Boa Vista & 31,1 \\
\hline Imigrante & 19,66 \\
Retirar & 10,27 \\
Abrigo & 9,01 \\
Receber & 6,72 \\
Semáforo & 4,99 \\
Civil & 4,99 \\
Prefeitura & 3,88 \\
\hline
\end{tabular}

Refugiados em Manaus

\begin{tabular}{ll}
\hline & $\boldsymbol{X}^{2}$ \\
\hline Manaus & 27,36 \\
\hline Mais & 18,59 \\
\hline Sair & 12,16 \\
\hline Passar & 12,16 \\
\hline Centro & 12,36 \\
\hline Abrigado & 9,03 \\
Fugir & 8,21 \\
\hline Ajudar & 5,37 \\
\hline Transferir & 5,37
\end{tabular}

Classe 3

Instituições governamentais

\begin{tabular}{|ll}
\hline & $\boldsymbol{X}^{\mathbf{2}}$ \\
\hline Federal & 17,8 \\
\hline Imigração & 17,15 \\
\hline Governo & 17,15 \\
\hline Amazonas & 16,88 \\
\hline Público & 9,17 \\
\hline Discutir & 9,17 \\
\hline Saúde & 6,05 \\
\hline Novo & 6,05 \\
\hline Refugiado & 5,57 \\
\hline Verba & 5,4 \\
\hline Plano & 5,4 \\
Ministério & 5,4 \\
Instalar & 5,4 \\
Especial & 5,4 \\
Emergência & 5,4 \\
\hline Decretar & 5,4 \\
Atender & 5,4 \\
İndio & 3,93 \\
\hline Atendimento & 3,89 \\
\hline
\end{tabular}

A CHD dividiu o corpus em 3 classes, em um primeiro momento dividindo em dois subcorpus, de um lado a classe 3 e do outro as classes 1 e 2, que em um segundo momento, foram subdivididas. Analisando a distribuição das reportagens dispostas em cada uma das classes, ao longo do ano de 2017, foi possível observar uma maior concentração de notícias agrupadas na classe 1, no mês de novembro, com 16; na classe 2, no mês de julho, com 7; e na classe 3, no mês de maio, com 16. 
Explorando o dendograma verifica-se que as classes 1 e 2 (Refugiados em Boa Vista e Refugiados em Manaus) agrupam em seu corpus reportagens que buscam apresentar as condições em que os refugiados se encontram na cidade de Boa Vista, capital do estado de Roraima, e Manaus, capital do estado do Amazonas. Nestas classes agrupam-se as reportagens que destacam a situação marginal dos refugiados, o descontentamento da população local para com as ações governamentais direcionadas a eles e as violências vividas cotidianamente.

Classe 1- Em Roraima falta abrigo para venezuelanos refugiados (BOM DIA AMAZONIA - 08/2017).

Classe 1 - Defesa civil divide imigrantes índios de não índios em Boa Vista (JORNAL DE RORAIMA - 11/2017).

Classe 1 - Liberação de benefícios para venezuelanos gera polêmica em Boa Vista (BOM DIA AMAZONIA - 09/2017).

Classe 2 - Famílias de venezuelanos fogem da fome e migram para 0 Brasil (BOM DIA AMAZONIA - 05/2017).

Classe 2 - Venezuelanos acampam na rodoviária de Manaus (JORNAL DO AMAZONAS - 02/2017).

Classe 2 - Mais de 100 venezuelanos seguem abrigados em rodoviária no Amazonas (JORNAL DO AMAZONAS - 03/2017).

Há também, nas classes 1 e 2, reportagens que evidenciam ações sociais, mediadas por ONGs, voluntários e igrejas, que buscam dar apoio aos refugiados. Essas notícias mostram ações de caráter humanitário que visam arrecadar alimentos, fornecer auxílio jurídico e ensinar o português.

Classe 2 - Artistas fazem evento para ajudar venezuelanos em Manaus (BOM DIA AMAZONIA - 06/2017).

Classe 1 - Grupo desenvolve curso de português gratuito a imigrantes venezuelanos em Boa Vista (BOM DIA AMAZONIA - 09/2017).

Classe 1 - Grupo leva atendimentos de saúde a venezuelanos em abrigo de Boa Vista (JORNAL DE RORAIMA - 12/2017).

$\mathrm{Na}$ classe 3 (Instituições governamentais) nota-se a evocação de palavras nos títulos das reportagens que demarcam as situações em que se encontram as cidades de Boa Vista e Manaus, e as medidas adotadas pelas instituições com a chegada dos venezuelanos. A maioria das reportagens que apresentam as ações governamentais e as condições emergenciais dos estados em função da chegada dos refugiados é referente ao governo do Amazonas.

Classe 3 - Defensoria Pública da União realiza atendimentos a imigrantes venezuelanos em abrigo de Roraima (JORNAL DE RORAIMA - 10/2017). 
Classe 3 - Governo Federal deve criar estrutura em Roraima para abrigar imigrantes venezuelanos (BOM DIA AMAZONIA - 06/2017).

Classe 3 - Manaus decreta emergência e aguarda recursos para ajudar imigrantes venezuelanos (JORNAL DO AMAZONAS - 05/2017).

Sobre o conteúdo das reportagens, percebe-se que palavras, como invasão, descontrole, ilegalidade, aumento de criminalidade, escassez de recursos e situação de emergência aparecem nas chamadas das reportagens televisionadas. Como apontado por Cogo (2006; 2007), em relação aos imigrantes, a mídia nacional constantemente produz narrativas nas quais os mesmos são vistos como violentos, criminosos, que impõem a violência e configuram-se, portanto, como problema social.

Nas reportagens analisadas, 79 noticiavam a situação de vulnerabilidade dos refugiados. Apresentavam as dificuldades do processo migratório, mostrando que os refugiados vendiam seus pertences ou faziam empréstimos com o intuito de conseguir recursos financeiros para arcarem com os custos da viagem. Tais reportagens ainda consideravam que, em função da crise política e econômica venezuelana, os refugiados, principalmente os indígenas, já chegavam ao Brasil em situação de vulnerabilidade.

Esses imigrantes, ao chegarem nas cidades de Manaus e Boa Vista, mesmo aqueles com um maior nível de escolarização, não têm total clareza dos problemas que vão enfrentar. Inicialmente, os refugiados objetivam conseguir um trabalho remunerado. Contudo, o trabalho formal se dará apenas após a regulamentação no país. Neste sentido, a mídia televisiva reporta, em 39 matérias, o aumento no número de pedidos de refúgio, o que fez com que aumentasse também a espera pela emissão de documentos. As reportagens apresentam dados da Polícia Federal e argumentam que a migração venezuelana começou timidamente em 2014, com apenas 9 pedidos de refúgios e que só no primeiro semestre de 2017, apenas no Estado de Roraima, foram registrados 5.787.

Outros fatores como a falta de estrutura física e a falta de pessoal capacitado para atuar no atendimento aos refugiados, fornecendo informações sobre assistência jurídica, obtenção de documentos etc., são apresentados como motivos que também influenciam a demora na regulamentação.

Nessas reportagens, as imagens de filas extensas são apresentadas com frequência. Nelas, os refugiados estão com o semblante cansado, sob sol, com malas e os filhos ao redor. Infere-se que muitas vezes essas imagens transmitidas pelas mídias se configuram como o primeiro contato que o público terá com o fato noticiado (MENASCHE, 2005). 
Essas imagens possuem um apelo mais intenso do que o discurso, colaborando para a consolidação da representação no imaginário popular (MENASCHE, 2005). Tais considerações vêm ao encontro com o que se observa em 92 reportagens, nas quais mesmo as que não tinham como tema a vulnerabilidade dos refugiados, imagens da falta de estrutura e condições de precariedade figuravam durante a veiculação das notícias.

Deve-se atentar para o fato de que as mesmas imagens são reprisadas inúmeras vezes em reportagens e jornais em meses diferentes. A repetição dessas imagens se constitui como um mecanismo para "organizar o julgamento", reafirmando sua posição social em relação ao "outro" (MOSCOVICI, 2010, p. 259), contribuindo para que as ideias sejam reforçadas.

Os telejornais veicularam também imagens das condições dos refugiados que se encontram em situação de rua. As reportagens apresentam que, por não terem para onde ir, muitos acampam nas ruas das cidades, vivendo em condições de quase animalidade, como se pode observar no trecho da reportagem Índios venezuelanos seguem em área da rodoviária de Manaus:

[...] sem qualquer higiene estas crianças tomam água em um prato depois de tê-lo colocado no chão. É ao lado de uma das principais avenidas de Manaus que a indígena se cobre com um fino lençol para trocar de roupa. Os riscos de doenças estão por todos os lados. Quem entra na rodoviária de início se depara logo com essa situação. Aqui famílias inteiras tomam banho e fazem suas necessidades na porta de entrada do terminal rodoviário, ou seja, quem passa consegue sentir o mau cheiro, o odor [...] (BOM DIA AMAZONAS - 05/2017).

Ao passo em que essas imagens são reproduzidas, as representações são reafirmadas. Inicia-se a demarcação das diferenças e os refugiados passam a ser apresentados como um fator de desordem. As representações convergem, o preconceito se estabelece e os venezuelanos começam a ser estigmatizados.

Os telejornais contribuem cotidianamente para a ampliação dessas representações, principalmente quando adotam um tom explicativo, mostrando as justificativas dos "estabelecidos" que associam a vinda dos "outsiders" a seus prejuízos econômicos. Em várias entrevistas os comerciantes argumentam como a presença dos refugiados na região tem dificultado as vendas. Os comerciantes afirmam que entendem os problemas pelos quais os refugiados vêm passando, mas que a presença deles vem espantando a freguesia. Goffman (1988) argumenta que constantemente estamos julgando, rotulando os indivíduos, elegendo o que caracterizamos como aceitável, 
evitando e estigmatizando o que foge a essa regra. Os estigmas são construídos a partir das relações de poder e podem ser considerados como a negação da identidade do outro.

Com o intuito de amenizar a situação de rua, foram criados abrigos tanto em Manaus, quanto em Boa Vista, para o acolhimento dos refugiados em situação de vulnerabilidade. As reportagens mostram que o abrigo é temporário e que o imigrante tem o prazo máximo de um mês para ali permanecer, mas há situações específicas para que esse tempo seja estendido.

Sobre esses abrigos, as reportagens reforçam novamente a ideia de precariedade. Os locais chamados de abrigos são, na verdade, ginásios esportivos. Nas reportagens analisadas 11 noticiam as poucas condições de saúde nesses locais, 11 apresentam a falta de alimento e 5 mostram falta de higiene.

[...] atualmente estão no abrigo quase 400 pessoas, a maioria índios Warao. Muitos passam a maior parte do tempo do lado de fora do ginásio onde estão as barracas montadas por eles. O líder indígena diz que a situação não é fácil, eles precisam de uma proteção melhor, principalmente para os dias de chuva, porque dentro do ginásio está muito apertado e à noite faz muito calor... No início do mês de junho o governo de Roraima recebeu quase meio milhão de reais do Governo Federal para investir no abrigo. Informou que o valor seria usado para conserto no ginásio, principalmente nos banheiros e também para comprar colchões e comida [...] (BOM DIA AMAZÔNIA - 07/2017).

Reforçando o poder visual (CHAMPAGNE, 2003; MENASCHE, 2005), as reportagens veiculam imagens de pessoas dormindo no chão, roupas empilhadas, moscas sobrevoando quem por ali dorme, famílias demarcando seu espaço com malas; as poucas condições de higiene são os focos destas notícias. Tais imagens reafirmam as dificuldades enfrentadas pelos refugiados, a ineficiência do governo, mas também a representação do migrante como sujo, doente e caótico.

Outro ponto de destaque diz respeito aos refugiados que não aceitam se alojar nesses abrigos. Dois motivos são apontados nas reportagens. O primeiro deles tem relação com conflitos étnicos e culturais, especificamente por se encontrarem entre os refugiados transferidos os índios da etnia Warao. Essa etnia é composta por diferentes grupos indígenas e entre alguns deles há conflitos históricos, motivo pelo qual não querem dividir o mesmo espaço. Além disso, foram evidenciados nos telejornais conflitos entre os indígenas e os não indígenas ${ }^{4}$. O motivo para o conflito seria, na visão dos não

\footnotetext{
${ }^{4}$ Termos utilizados pelos telejornais.
} 
indígenas, o acesso desigual às políticas públicas, uma vez que o governo brasileiro oferece "vantagens" aos indígenas, como, por exemplo, um maior tempo de permanência no abrigo. Assim, os Warao que decidem ficar no abrigo preferem se alojar do lado de fora, nas intermediações. As reportagens mostram que as barracas do lado de fora do abrigo são improvisadas em um local que não tem mínimas condições de saneamento, além da falta de água. Faz-se pertinente expor que ao retratarem tal conflito, os telejornais recorrem a estereótipos, apresentando-o como infundado e banal, demonstrando como a ausência de aspectos culturais semelhantes entre os grupos dificulta o compartilhamento de códigos e a integração local (SAYAD, 1988; CRISP, 2004). O segundo motivo que leva os refugiados a saírem dos abrigos diz respeito à superlotação e muitos refugiados preferem, então, voltar às ruas a conviver com a situação de precariedade dos abrigos.

Essas migrações, muitas vezes de caráter provisório, tendem a se prolongar indefinidamente (SAYAD, 1988). Assim, com o intuito de se estabilizarem no país de destino, os refugiados anseiam conseguir uma atividade remunerada. Os telejornais apresentam que, como estratégia para conseguir dinheiro, muitos venezuelanos, em especial os indígenas, são pedintes nos semáforos do centro das cidades de Boa Vista e Manaus. Temos novamente a veiculação de imagens que retratam aspectos negativos dos refugiados. Nestas, as mulheres indígenas pedem esmolas nas ruas, transitando perigosamente entre os carros, carregando crianças de colo ou com seus filhos agarrados na barra de suas saias. A mulher indígena deixa de ser uma pessoa em situação de vulnerabilidade para se tornar a mãe irresponsável que transita com seus filhos pequenos em avenidas movimentadas.

Ainda sobre a presença de venezuelanos nos semáforos, algumas reportagens mostram o descontentamento da população local que se sente coagida a contratar seus serviços e pressiona as autoridades para retirá-los dos espaços públicos.

[...] A Guarda Civil municipal retirou os materiais de trabalho e pediu que os venezuelanos deixem os sinais e os espaços públicos da cidade. A prefeitura disse que a iniciativa foi um pedido dos próprios moradores da capital... A ação mobilizou vários agentes da Guarda Civil que, armados, chegaram aos sinais e pediram a saída dos estrangeiros, além de levar materiais de trabalho e alimentos vendidos por eles. Tudo sem oferecer nenhum tipo de assistência. É o que afirma Marcile, que também limpa para-brisas do semáforo para ajudar no sustento da família [...] (BOM DIA AMAZONIA - 11/2017). 
Ademais, essas mesmas reportagens mostram que o acesso a um emprego formal depende de vários fatores, como documentação, escolaridade, domínio do português e o estabelecimento de contatos que o indiquem ao empregador. As matérias veiculadas apresentam o esforço feito por entidades religiosas e ONGs para que os refugiados consigam cumprir tais requisitos e conquistem um trabalho remunerado.

Em 11 reportagens é destacado que os refugiados aceitam condições precárias de trabalho por necessidade. São veiculadas imagens de venezuelanos com posse de seus documentos, o que para eles seriam um passaporte para um trabalho, pedindo emprego no semáforo com cartazes confeccionados com papelão.

Essas notícias apresentam dados de uma pesquisa realizada pelo Ministério do Trabalho, que revelou que $60 \%$ dos venezuelanos refugiados no Brasil estão aceitando trabalhos para receber menos que um salário mínimo. Apresentou-se também que 32\% deles possuem graduação ou pós-graduação e que isso não tem sido garantia de boas condições de emprego. A vulnerabilidade dos refugiados também inclui exploração pelos traficantes de pessoas, como é possível observar na reportagem "Ministério Público de Roraima investiga suposta exploração da mão de obra venezuelana".

[...] O Ministério Público do Trabalho está investigando um possível caso de exploração de mão de obra de venezuelanos. Segundo uma denúncia, imigrantes estariam sendo levados para trabalhar em outro estado. Se o caso for comprovado, será o segundo só este ano. No primeiro a empresa foi condenada a pagar quase 70 mil reais por danos morais coletivos ... existe a denúncia de suspeita de tráfico de pessoas, de que pessoas estão sendo aliciadas aqui e remetidas para outros estados da federação [...] (JORNAL DE RORAIMA - 10/2017).

Os refugiados são, muitas vezes, recrutados por meio de anúncios falsos que prometem boas condições de trabalho (POMPEU et al, 2014) e alegam que, embora o salário que recebem seja insuficiente para arcar com as despesas, ainda assim, preferem se submeter a estas condições do que voltar à Venezuela. Segundo eles, as condições para aquisição de alimentos são piores em seu país de origem. Além disso, as notícias expõem denúncias anônimas de que há venezuelanos trabalhando em condições análogas ao trabalho escravo.

Outro ponto de destaque diz respeito às reportagens que noticiam que, apesar da abertura das fronteiras aos venezuelanos, os governos municipais e estaduais não dispõem de recursos suficientes para receber e alojar aqueles que se refugiam no Brasil. Nestas, disserta-se sobre a falta de recursos econômicos para manutenção do patrimônio 
e serviços públicos em função do grande número de refugiados venezuelanos que chegaram às cidades. Como dito anteriormente, a mídia se constitui como um dos meios de comunicação onde as representações são formadas e ressignificadas; assim, tais reportagens ajudam a reforçar o medo e a aversão aos venezuelanos, e a população passa a reconhecê-los como concorrentes ou usurpadores dos recursos públicos locais.

Por este ângulo, pode-se perceber que a xenofobia se caracteriza como outro motivo noticiado pelos telejornais que vêm impedindo os venezuelanos de conseguirem emprego e viver nas cidades de Boa Vista e Manaus.

A UNHCR (2012) aponta que com a entrada massiva de estrangeiros, a população local tende a vê-los como uma ameaça, pois competem por emprego e recursos governamentais, dando origem aos comportamentos xenófobos, como podemos ver na reportagem abaixo.

[...] O Freyo é empreendedor venezuelano que atua em Roraima há mais de um ano. Fugiu da crise no país vizinho, mas por aqui tem enfrentado dificuldades. Está em um novo ponto comercial porque a dona do antigo endereço alugado por ele quebrou o contrato [...] (JORNAL DE RORAIMA $-18 / 08 / 2017)$.

A matéria em questão expõe que Freyo, um comerciante venezuelano, teve seu contrato rompido por receber em sua residência e estabelecimento refugiados venezuelanos, bem como por ser presidente da Associação dos Venezuelanos no Brasil. $\mathrm{Na}$ reportagem, Freyo afirma que a proprietária do imóvel relatou não gostar de venezuelanos e por isso desejava que ele se retirasse. Os repórteres destacam que o rompimento do contrato com Freyo, em função de sua nacionalidade, se configura como xenofobia e acentuam que os estrangeiros regulares no Brasil são amparados pela lei e podem denunciar os ataques xenofóbicos, o que pode resultar em condenação de até três anos de reclusão.

Como observado por Cogo $(2012 ; 2015)$, os imigrantes, com intuito de darem suporte e apoio para pessoas da mesma nacionalidade, criam redes de sociabilidade. Percebe-se o estabelecimento de uma dessas redes tendo Freyo como figura central. A consolidação dessa rede pode tornar o processo de inserção local um pouco mais fácil, mas em um contexto de midiatização da falta de emprego e o alarmismo que se faz em relação aos refugiados, é provável que o estabelecimento dessa rede, somado ao estigma 
que Freyo carrega por ser um refugiado, tenha influenciado o ato xenofóbico da proprietária do imóvel.

Ainda sobre a xenofobia, outras notícias televisionadas argumentam que o estopim para a onda de preconceito teria sido a liberação de recursos financeiros para os venezuelanos, especificamente no caso de Boa Vista, através do "aluguel solidário" ${ }^{\text {. A }}$ reportagem do Jornal de Roraima, televisionada no dia 28/08/2017, cobriu uma manifestação contra o "aluguel solidário". É possível ver em um dos cartazes dos manifestantes a frase " $E$ a nossa prefeita foi a Brasília buscar melhores condições de vida para os estrangeiros (sem-xenofobia). E nós brasileiros como ficamos?"6.

Uma vez que o Brasil passa por um momento de instabilidade econômica e com alto percentual de desemprego, faz-se pertinente evidenciar que os ataques xenofóbicos se dão, em sua maioria, em função do descontentamento da população local para com as ações governamentais. Estas ações buscam auxiliar financeiramente os refugiados venezuelanos, mas acabam enfatizando no imaginário popular a ideia do "outro" ameaçador que se infiltra em nossa sociedade e expropria nossos recursos (COGO, 2016). Ressalta-se que as reportagens, ao noticiarem os ataques xenofóbicos, quando não retratam casos específicos, veiculam imagens de ofensas destinadas aos venezuelanos publicadas no facebook, twitter etc.

Um dado relevante e passível de passar desapercebido diz respeito à violência simbólica vivenciada pelos refugiados. Observamos que nos primeiros meses as reportagens não utilizavam 0 Geradores de Caracteres $(G C)^{7}$ para identificar os venezuelanos entrevistados. Contudo, estas mesmas reportagens, para todos os outros entrevistados, traziam nos GCs informações como o nome, ocupação, etc. O refugiado, aqui, é representado como um sujeito sem nome, sem identidade e apátrida, que não compartilha, portanto, dos nossos códigos culturais de cidadania, pessoalidade, territorialidade e pertença social.

\section{Conclusão}

\footnotetext{
${ }^{5}$ Recurso financeiro destinado ao pagamento de aluguel temporário para famílias refugiadas em situação de rua.

6 Texto original do cartaz - "E a nossa prefeita foi a Brasília buscar condições melhor de vida aos estrangeiros (sem-xenofobia) E nós como ficamos Brasileiros!"

7 Um tipo de legenda inserida na parte inferior ou no canto da tela utilizada para identificar e mostrar informações sobre o entrevistado.
} 
A mídia, ao dar visibilidade aos refugiados venezuelanos, tematiza, hierarquiza e (re)atualiza representações que circulam no imaginário popular. Ela tem o poder de selecionar o que será ou não transmitido à população. Dessa forma, as violências vivenciadas pelos refugiados serão transmitidas levando-se em consideração os interesses de quem as reproduzem, mas também os sentimentos difusos da sociedade em relação a um determinado fato. Neste sentido, os telejornais oscilam entre um viés discursivo de cunho humanitário e outro que reforça os preconceitos em relação ao "outro".

Ressalta-se que a forma como as reportagens são apresentadas tendem a influenciar o público a representar negativamente os refugiados. Por meio da repetição de imagens da vulnerabilidade e das condições precárias vividas pelos refugiados, os telejornais reforçam a ideia de insegurança proporcionada pela presença desses forasteiros.

Não obstante, a situação econômica brasileira é outro fator que, somado às reportagens, contribui para o surgimento de comportamentos xenófobos, gerando no espectador um sentimento de injustiça e ódio, pois o refugiado deixa de ser percebido como frágil e torna-se um competidor por recursos de diversas ordens e magnitudes.

A cobertura jornalística sobre a migração venezuelana mostra que as mídias, ao reportarem um acontecimento, voltam-se a um fato concreto e é essa concretude que provoca no público a necessidade de rever ou sancionar ideias, até então genéricas e difusas sobre os imigrantes, porque agora tem-se um objeto específico, os venezuelanos, que podem ser vistos, ouvidos, focalizados. Ao enquadrarem esse objeto, as imagens e discursos jornalísticos permitem uma ancoragem, ou seja, ideias gerais tornam-se verdade.

As representações sobre os refugiados circulam por um conjunto heterogêneo de discursos e as formas como são transmitidas influenciam o imaginário popular, favorecendo o (re)surgimento dos estereótipos e das violências entre quem representa e quem é representado. Se, como viu-se, o representado evoca sentimentos xenofóbicos de medo e insegurança e, ao mesmo tempo, sentimentos de compaixão, essa polissemia também vale para quem representa, pois seus sentimentos oscilam entre a repulsa e o acolhimento humanitário.

Reitera-se o telejornalismo como um grande produtor de sentidos e o poder do mesmo em contribuir para que novos discursos figurem no imaginário popular. Desse 
modo, ao deixar de enquadrar os aspectos "extraordinários" da vida dos refugiados venezuelanos no Brasil e ao viabilizar a construção de narrativas pela ótica dos mesmos, possivelmente, poderia contribuir para minimizar as representações negativas do público sobre os refugiados.

\section{Referências}

AYDOS, Mariana; BAENINGER, Rosana; DOMINGUEZ, Juliana A. Condições de Vida da População Refugiada no Brasil: trajetórias migratórias e arranjos familiares. III Congresso da Associação Latino Americana de População, ALAP, Córdoba, 2008.

Disponível em: <

http://www.faed.udesc.br/arquivos/id_submenu/1416/artigo_sobre_refugiados_2008_mrj.p df > Acesso em: 11 de set. 2019.

BRASIL. Número de Imigrantes trabalhadores no País cresceu 131\%, Portal Brasil. Disponível em: < http://www.brasil.gov.br/economia-e-emprego/2016/12/numero-detrabalhadores-imigrantes-no-pais-cresceu-131/carteira-de-trabalho.jpg/view >. Acesso em: 20 de Ago. 2018.

BUENO, Magali. F. O imaginário sobre a Amazônia: Um a leitura por meio dos discursos dos viajantes, do Estado, dos livros didáticos de Geografia e mídia impressa. Dissertação (Programa de Pós-Graduação em Geografia Humana), Universidade de São Paulo, USP, São Paulo, 2002.

CAMARGO, Brigidio V.; JUSTO, Ana M. IRAMUTEQ: um software gratuito para análise de dados textuais. Temas em Psicologia, vol. 21, ㄲo2, 2013.

CHAMPAGNE, Patrick. A visão mediática. In Bourdieu Pierre (Org.), A miséria do mundo. Petrópolis-RJ: Vozes, 2003.

COGO, Denise. Entre a fuga e a invasão: alteridade e cidadania da imigração haitiana na mídia brasileira. Famecos, Porto Alegre, vol. 23, no 1, 2016. Disponível em: < http://revistaseletronicas.pucrs.br/fefid/ojs/index.php/revistafamecos/article/view/21885 > Acesso em: 11 de set. 2019.

Internet e redes migratórias transnacionais: narrativas da diáspora sobre o Brasil como país de imigração. Novos Olhares, vol. 4, n. 1, p. 91-104, 2015. Disponível em: < http://www.revistas.usp.br/novosolhares/article/view/102224 > Acesso em: 11 de set. 2019.

Latino-americanos em diáspora: usos de mídias e cidadania das migrações transnacionais. Rio de Janeiro: Tríbia, 2012.

CONARE, Comitê Nacional para os Refugiados, Relatório Refúgio em Números - $3^{a}$ edição, 2018. Disponível em: <http://www.acnur.org/portugues/wpcontent/uploads/2018/04/refugio-em-numeros_1104.pdf>. Acesso em: 20 de Ago. 2018. 
CRISP, Jeff. The local integration and local settlement of refugees: a conceptual and historical analysis. New Issues in Refugee Research, Geneva, UNHCR, 2004. Disponível em: http:<//www.unhcr.org/research/working/407d3b762/local-integration-local-settlementrefugees-conceptual-historical-analysis.html>. Acesso em: 2017.

DARDE, Vicente. W. da S.; LEME, Fernando. A. Telejornalismo, narrativas e representações: um estudo sobre o aniversário da cidade de São Paulo no SPTV. Rumores, vol. 10, $\mathrm{n}$.20, p. 288-309. 2016. Disponível em: <http://www.revistas.usp.br/Rumores/article/view/117144> Acesso em: 11 de nov. 2018.

ELIAS, Norbert.; SCOTSON, John. L. Os Estabelecidos e os Outsiders: sociologia das relações de poder a partir de uma pequena comunidade. Rio de Janeiro: Jorge Zahar Editor, 2000.

GLOBO, História - Grupo Globo, 2013. Disponível em: <http://historiagrupoglobo .globo.com/hgg/index.htm>. Acesso em: 11 de nov. 2018.

GOFFMAN, Erving. Estigma - Notas Sobre a Manipulação da Identidade Deteriorada. Rio de Janeiro: LTC, 1988.

IBGE - Instituto Brasileiro de Geografia e Estatística. Pesquisa Nacional por Amostra de Domicílios Contínua - Trimestral, 2018. Disponível em: < https://ww2.ibge.gov.br/home /estatistica /indicadores/trabalhoerendimento /pnad_continua/default.shtm>. Acesso em: 15 de nov. 2018.

JODELET, Denise. Representações Sociais: um domínio em expansão. In JodeleT Denise, (Org.), As representações sociais, Rio de Janeiro, p. 17-44. 2001.

LAKATOS, Eva M.; Marconi, Marina de A. Metodologia do trabalho cientifico: procedimentos básicos, pesquisa bibliográfica, projeto e relatório, publicações e trabalhos científicos. São Paulo: Atlas, 2001.

MORAES, I. A. de; ANDRADE, C. A. A. de; MATTOS, B, R. B. A imigração haitiana para o brasil: causas e desafios. Conjuntura Austral, vol. 4, n. 20; p. 95-114. 2013. Disponível em: < https://seer.ufrgs.br/ConjunturaAustral/article/view/35798 > Acesso em: 15 de nov. 2018.

MOREIRA, Juliana. B. Redemocratização e direitos humanos: a política para refugiados no Brasil. Revista Brasileira de Política Internacional, no 53, p. 111-129. 2010.

Disponível em: https://www.scielo.br/pdf/rbpi/v53n1/a06v53n1.pdf> Acesso em: 15 de nov. 2018.

MOSCOVICI, Serge. Representações Sociais: Investigações em Psicologia Social. Tradução de Pedrinho A. Guareschi,Petrópolis, Vozes, 2010.

OLIVEIRA, Márcia M. A mobilidade humana na tríplice fronteira: Peru, Brasil e Colômbia. Dossiê Migração, Estudos Avançados, vol. 20, n. 57, São Paulo, 2006. Disponível em: < https://www.scielo.br/pdf/ea/v20n57/a14v2057.pdf > Acesso em: 15 de nov. 2018. 
PESAVENTO, Sandra. J. Catarina Come-Gente. Imaginário, n. 4, p. 48-58. 1998.

POMPEU, Gina. V. M.; Cartaxo Marina. A.; Cardoso N. M. Políticas públicas, trabalho e fronteiras. Revista de direito brasileira, vol. 8, p. 233-274. 2014. Disponível em: <https://www.indexlaw.org/index.php/rdb/article/view/2892/2694> Acesso em: 15 de nov. 2018.

RODRIGUES, Francilene. Migração transfronteiriça na Venezuela. Estudos Avançados, vol. 20, n. 57, São Paulo, 2006. Disponível em: <https://www.scielo.br/pdf/ea/v20n57/a15v2057.pdf> Acesso em: 15 de nov. 2018.

SAYAD, Abdelmalek. A Imigração ou os Paradoxos da Alteridade. São Paulo: Edusp, 1998.

SÊGA, Rafael. A. O conceito de representação social nas obras de Denise Jodelet e Serge Moscovici. Anos 90, n. 13, p. 128-133. 2000.

ODALIA, Nilo. O que é violência. São Paulo: Brasiliense, 2004.

UNHCR, United Nations High Commissioner for Refugees, Actualidad en Argentina, Bolivia, Brasil, Chile, Paraguay y Uruguay, 2002. Disponível em:

<http://www.unhcr.org>. Acesso em: 15 de nov. 2018.

UNHCR, United Nations High Commissioner for Refugees, Mid-year trends 2016.

Disponível em: <http://www.unhcr.org/statistics/unhcrstats/58aa8f247/mid-year-trendsjune-2016.html>. Acesso em: 15 de nov. 2018.

UNHCR, United Nations High Commissioner for Refugees, The state of the World's Refugees In Search of Solidarity, The office of the United Nations High Commissioner for Refugees, 2012. Disponivel em:

<http://www.unhcr.org/4fc5ceca9.html\#_ga=2.108475654.589067947.1524569037992897357.1524569037>. Acesso em: 15 de nov. 2018.

Recebido: 11 maio 2020

Aprovado: 17 julho 2020 